\title{
Hello World: 17 habilidades para exercitar desde o início da graduação em Computação
}

\author{
Roberto Pereira \\ Universidade Federal do Paraná \\ Curitiba, Brasil \\ rpereira@inf.ufpr.br
}

\author{
Leticia M. Peres \\ Universidade Federal do Paraná \\ Curitiba, Brasil \\ lmperes@inf.ufpr.br
}

\author{
Fabiano Silva \\ Universidade Federal do Paraná \\ Curitiba, Brasil \\ fabiano@inf.ufpr.br
}

\section{RESUMO}

Reconhecendo diferentes desafios do ensino de Computação e conscientes do contexto situado em que atuamos, desde 2019 oferecemos uma disciplina de Introdução à Ciência da Computação, como disciplina curricular obrigatória, no primeiro semestre do curso de Bacharelado em Ciência da Computação. Nessa disciplina, a ementa, o conteúdo programático e as estratégias didáticas têm o propósito de exercitar 17 habilidades que consideramos essenciais para profissionais da área de Computação (tanto no sentido técnico quanto social e ético), além de situar estudantes na área e no curso escolhidos. Neste artigo apresentamos um relato da disciplina, das 17 habilidades que ela se propõe a exercitar, da nossa estratégia didática e dos resultados de nossa experiência com a sua aplicação de forma totalmente remota. Com base na observação docente e na opinião discente obtida por meio de um questionário online, identificamos que a disciplina foi efetiva em promover o exercício das diferentes habilidades, que foi capaz de ampliar o entendimento discente sobre o curso e sobre a responsabilidade profissional, e que o formato remoto apresentou mais vantagens do que desvantagens para a estratégia didática empregada. Os resultados também revelaram aspectos da estratégia didática que foram bem sucedidos e aspectos que ainda precisam ser aprimorados.

\section{PALAVRAS-CHAVE}

pensamento computacional, responsabilidade social, resolução de problemas, introdução à computação

\section{INTRODUÇÃO}

Nas recomendações de currículo da ACM e IEEE [13] são descritas algumas das características esperadas de profissionais graduados em Ciência da Computação: 1. Compreensão técnica da ciência da computação; 2. Familiaridade com temas e princípios comuns; 3. Apreciação da interação entre teoria e prática; 4. Perspectiva em nível de sistema; 5. Habilidades para resolver problemas; 6. Experiência de projeto; 7. Compromisso com a aprendizagem ao longo da vida; 8. Compromisso com a responsabilidade profissional; 9. Habilidades de comunicação e organização; 10. Conscientização da ampla aplicabilidade da Computação; e 11. Apreciação do conhecimento específico do domínio.

Fica permitido ao(s) autor(es) ou a terceiros a reprodução ou distribuição, em parte ou no todo, do material extraído dessa obra, de forma verbatim, adaptada ou remixada, bem como a criação ou produção a partir do conteúdo dessa obra, para fins não comerciais, desde que sejam atribuídos os devidos créditos à criação original, sob os termos da licença CC BY-NC 4.0.

EduComp'21, Abril 27-30, 2021, Jataí, Goiás, Brasil (On-line)

(c) 2021 Copyright mantido pelo(s) autor(es). Direitos de publicação licenciados à Sociedade Brasileira de Computação (SBC).
Para que as pessoas desenvolvam (exercitem) essas características, a grade curricular de um curso de Computação deve oferecer disciplinas que as promovam de forma explícita e articulada. É esperado que algumas disciplinas cubram uma ou mais dessas características devido ao conteúdo trabalhado. Entretanto, das 11 características listadas, apenas as duas primeiras podem ser facilmente mapeadas a itens de ementas e de conteúdos programáticos de disciplinas; as outras 9 dependem fortemente do método didático empregado e da contextualização do ensino.

No nosso ponto de vista, não basta oferecer uma disciplina (ou um conjunto de disciplinas), conduzir atividades para exercício e assimilação dos conceitos e técnicas da Computação e falar da importância de aspectos humanos, se a condução e discussões não articularem teoria e prática, se essa prática não for situada em contextos relevantes e interessantes e se alunos e alunas não forem engajados e provocados a adotar uma postura participativa e autônoma. Portanto, é preciso promover o desenvolvimento das características listadas desde o início dos cursos de Computação, adotando um método didático que possa influenciar a percepção discente e a sua postura durante o curso.

No documento da ACM e IEEE [13] é destacado ainda que "the education that undergraduates in computer science receive must adequately prepare them for the workforce in a more holistic way than simply conveying technical facts. Indeed, soft skills (such as teamwork, verbal and written communication, time management, problem solving, and flexibility) and personal attributes (such as risk tolerance, collegiality, patience, work ethic, identification of opportunity, sense of social responsibility, and appreciation for diversity) play a critical role in the workplace. Successfully applying technical knowledge in practice often requires an ability to tolerate ambiguity and to negotiate and work well with others from different backgrounds and disciplines. These overarching considerations are important for promoting successful professional practice in a variety of career paths".

Em seu artigo na Communications of the ACM, Guzdial [12] reflete sobre o melhor modo de ensinar Ciência da Computação para iniciantes e sugere uma abordagem híbrida na qual os estudantes se engajam em uma variedade de atividades, com ênfase inicial em atividades que não requeiram o uso de uma linguagem de programação.

Ao investigar o desenvolvimento de habilidades (perícias) na programação de computadores, Maschio [15] estende o conjunto de habilidades proposto por Pimentel e Direne [20], sugerindo diversos indícios que variam da precisão sintática e semântica ao autoconhecimento sobre habilidades metacognitivas. Andrade et al. [1], por sua vez, argumentam que estudantes de Computação devem ser estimulados a desenvolver diferentes tipos de pensamento: (i) o abstrato, utilizando diferentes níveis de subjetividade 
para compreender um problema; (ii) o algorítmico, demonstrando soluções de problemas em diferentes passos de forma a encontrar a resposta mais eficiente e eficaz; (iii) o lógico, formulando e eliminando hipóteses; e (iv) o dimensionável, compondo ou decompondo um problema para formular uma solução complexa.

Tanto os tipos de pensamento quanto habilidades de programadores peritos e características de profissionais da Computação, podem ser promovidos em disciplinas que propiciem a experiência com atividades "desplugadas"[2] e práticas que convidem a entender e propor soluções computacionais para problemas desafiadores, socializando práticas e discutindo suas implicações éticas. Os resultados dessas práticas devem ser utilizados como contexto para a discussão e exemplificação das áreas da Computação e possibilidades de atuação. Devem ser utilizados, também, para promover a consciência sobre as responsabilidades éticas e profissionais, e para despertar a curiosidade discente para as demais disciplinas que serão trabalhadas no curso. Considerando esses elementos, em uma reforma curricular no ano de 2017 do curso de Bacharelado em Ciência da Computação da Universidade Federal do Paraná (UFPR), identificamos um conjunto de 17 habilidades que julgamos essenciais desde o início do curso e propusemos uma disciplina para trabalhar essas habilidades no primeiro semestre.

Por habilidade, consideramos: "1. Qualidade daquele que é hábil; 2. Capacidade, inteligência; 3. Destreza; 4. Astúcia, manha. 5. Aptidão, engenho." ${ }^{1}$. Enxergamos afinidades deste conceito com o ensino baseado em competências [23], porém preferimos o termo habilidades e o entendemos como qualidades que pessoas podem exercitar e aprimorar.

Para exercitar esse conjunto de habilidades, a disciplina foi concebida em 3 eixos: 1 . Introdução à Ciência da Computação, para situar discentes ingressantes na área e no curso de Computação escolhido; 2. Pensamento Computacional, para promover habilidades de resolução de problemas utilizando conhecimento computacional e introdução à noção de algoritmos independente de linguagem de programação; e 3. Atuação e Responsabilidade Profissional, para apresentar as possibilidades de atuação profissional na indústria e academia, promovendo o desenvolvimento de habilidades críticas para o exercício da profissão de forma competente e responsável. Esta disciplina está sendo oferecida desde o primeiro semestre de 2019 e vem se mostrando capaz de atender aos objetivos propostos.

Neste relato, descrevemos as 17 habilidades que julgamos importantes de serem abordadas desde o início da formação em Computação, apresentando uma disciplina concebida para exercitá-las. Para possibilitar o entendimento e replicação da iniciativa em outros contextos, apresentamos a ementa da disciplina e o seu conteúdo programático, e relatamos a nossa experiência com a sua aplicação em formato totalmente remoto no segundo semestre de 2020, trazendo os resultados de um questionário para avaliação discente e nossas lições aprendidas. Para possibilitar a replicação de nossos estudos em outros cenários, disponibilizamos ao final do artigo os endereços aos materiais de apoio, incluindo o acesso a uma instância Moodle totalmente configurada para a disciplina.

\footnotetext{
${ }^{1}$ Dicionário Priberam da Língua Portuguesa, https://dicionario.priberam.org/habilidade [consultado em 23-01-2021]
}

\section{HABILIDADES ESSENCIAIS}

Segundo Giraffa e Muller [10], estudantes têm chegado à universidade com deficiências variadas em sua formação: de deficiências relacionadas à expressão escrita e interpretação de textos até hábitos de estudo, pesquisa e conhecimentos de Matemática. Embora essas deficiências tenham se intensificado nos últimos anos devido a diferentes problemas na educação de base, as autoras destacam que: "Não adianta apenas o professor constatar isto e dizer que os estudantes já vieram com os referidos déficits. O fato é que após passarem nos exames seletivos eles se tornam universitários e passam a ser responsabilidade da universidade e, por consequência, dos seus professores. Cabe aos docentes e gestores buscarem soluções para transpor estas lacunas no aprendizado pregresso destes estudantes."[10])

Em 2017, durante a reforma curricular do curso de Bacharelado em Ciência da Computação da UFPR, nosso corpo docente implementou diferentes ações para reduzir a evasão e melhorar a qualidade da formação discente. Dentre essas ações conduzidas coletivamente pelos docentes do Departamento de Informática, uma nova disciplina foi concebida para o primeiro semestre do curso com o propósito de situar os/as ingressantes no curso e na área, exercitando habilidades essenciais para as demais disciplinas e para o exercício profissional.

Para identificar as habilidades e para propor uma disciplina de Introdução à Ciência da Computação (ICC) que as exercitasse, nós reconhecemos a necessidade de se entender tanto os fundamentos, práticas e habilidades universais da Ciência da Computação, quanto o contexto situado no qual essa disciplina seria ofertada. Como contexto, consideramos uma universidade pública, de um país com desigualdades estruturais, com um público-alvo que possui deficiências em sua formação prévia. Entendemos, em nossa atuação, que é papel da universidade pública brasileira capacitar profissionais capazes de contribuir com o contexto social desafiador de nosso país, e que essa capacitação muitas vezes demanda oferecer a base para que discentes consigam acompanhar as disciplinas do curso escolhido. Sem a preocupação com essa preparação de base, a universidade pública corre o risco de se tornar um espaço elitista no qual as pessoas advindas de um ensino básico deficiente não conseguem permanecer.

\subsection{Justificativas}

Para identificar o conjunto de habilidades consultamos ${ }^{2}: 1$. as recomendações internacionais da ACM e IEEE [13] e currículos de universidades estrangeiras (e.g., Stanford, Oxford, Carnegie Mellon), como modo de manter em mente as habilidades que se espera de cientistas da Computação reconhecendo o perfil profissional que se deseja capacitar; e 2. as recomendações da Sociedade Brasileira de Computação (SBC) [26] e currículos de outras universidades do país (e.g., PUC-Rio, PUCRS, UFSC, UFMG, UNICAMP, USP, UFPE, UTFPR), referências em Educação e Computação situadas na realidade brasileira, como uma forma de olhar para esta realidade reconhecendo o perfil discente que chega ao curso e a diversidade de desafios que enfrentamos.

\footnotetext{
${ }^{2}$ As consultas foram realizadas entre setembro e outubro de 2017 diretamente na página dos cursos das instituições citadas. O processo de consulta foi exploratório.
} 
Duas abordagens comuns em currículos são: (1) apresentar as áreas e conteúdos em profundidade razoável para oferecer uma visão e entendimento sobre o que está sendo exposto; e (2) apresentar uma visão em largura, com conceitos básicos e contextualização, para então aprofundar em áreas específicas. A disponibilização de disciplinas introdutórias em um currículo normalmente visa oferecer uma visão em largura sobre uma área ou subáreas de modo a permitir o subsequente aprofundamento.

Nas três instituições estrangeiras consultadas, Stanford, Oxford e Carnegie Mellon, o curso introdutório mais básico identificado foi um curso de introdução à programação para que estudantes já comecem a desenvolver seu entendimento básico de algoritmos e estrutura de dados utilizando uma linguagem de programação. Disciplinas introdutórias devem ser pensadas com foco no públicoalvo, nas condições das pessoas que iniciam o curso e sua formação básica. Isso explica parcialmente o porquê das três instituições não se preocuparem com alguma disciplina de caráter mais básico que introdução à programação.

Nos cursos de Computação das 10 instituições brasileiras consultadas o quadro era mais diversificado. Os cursos da PUC-Rio, UNICAMP e UFPE apresentavam apenas introdução à programação (ou de fundamentos de programação). UFSCar, USP-ICMC e USP-IME ofereciam uma disciplina introdutória na forma de Seminários com docentes e ex-discentes. UFMG, PUCRS, UFSC e UTFPR ofereciam uma disciplina para trabalhar desde conceitos básicos e história da Computação até aspectos de atuação profissional, incluindo questões éticas. UFMG focava na apresentação de seu curso e no desenvolvimento de estratégias pessoais para a formação discente; UFSC se preocupava em oferecer uma visão em largura das áreas da Computação; enquanto UTFPR e PUCRS focavam em promover habilidades de pensamento computacional, com PUCRS focando na resolução de problemas computacionais e construção de algoritmos, e UTFPR focando nos aspectos sociais, éticos e políticos na Computação e na prática profissional. O método didático predominante identificado nessas quatro instituições era a condução das aulas de forma expositiva com exercícios práticos.

O conjunto das disciplinas consultadas permitiu identificar 3 preocupações, ou objetivos gerais, para a formação de discentes ingressantes: 1. Situar discentes ingressantes na área e no curso de Computação; 2. Promover habilidades de resolução de problemas utilizando conhecimento computacional e introdução à noção de algoritmos independente de linguagem; e 3. Apresentar as possibilidades de atuação profissional e a responsabilidade nessa atuação.

Para obter outras visões e opiniões sobre desafios e necessidades discentes, um formulário online foi compartilhado na página do curso no Facebook convidando as pessoas graduandas e graduadas em Computação a resgatar suas experiências e responder, de forma livre: 1. Quais suas maiores dificuldades ao iniciar o curso de Computação? 2. Que tipo de disciplina introdutória você gostaria de ter feito no seu $1^{\circ}$ semestre da graduação em Computação? e 3. Sugestões e comentários gerais. Intencionalmente, nenhuma questão era obrigatória e nenhum outro questionamento ou direcionamento foi incluído. Em um período de 4 dias o formulário recebeu 16 respostas, sendo 10 de estudantes da Computação, 3 de profissionais da área acadêmica e 2 da indústria; um respondente não se identificou.

Para a questão 1, identificamos: Dificuldades com disciplinas de Matemática; "Descontextualização" dos conteúdos e exemplos;
Quebra de expectativas; Falta de uma visão geral e "realista" sobre a área e sobre o curso; Falta de iniciativa nos estudos; e Dificuldades de desenvolver o pensamento abstrato, lógico e computacional.

Para a questão 2, diversos itens foram citados, tais como: Apresentação do curso, grade curricular e preparação para "o que está por vir”; Apresentação do departamento, sua infraestrutura e grupos de pesquisa; Conceitos básicos em Computação; Conceitos básicos de matemática para a Computação; Escrita; História da Computação; Aplicações e implicações na sociedade; Pensamento computacional independente de linguagem; Possibilidades de atuação profissional na academia e na indústria; Uso de ferramentas e ambientes necessários para o curso; e Visão geral da Computação e suas áreas.

Finalmente, como sugestões gerais dos respondentes, os principais apontamentos estavam alinhados com: Disciplina introdutória que apresente conceitos da Computação; História da Computação; Mostrar a realidade da vida acadêmica, preparando para o que será encontrado e trabalhado no curso; Promover interesse pela iniciação científica e empreendedorismo; Entender o porquê de aprender cada matéria do curso; e Utilizar metodologias ativas, com aprendizado baseado em projetos, em problemas ou em equipes.

Embora a quantidade de respondentes não seja suficiente para fundamentar afirmações e conclusões, as respostas refletiram a percepção do público respondente sobre a necessidade de uma disciplina que atenda aos 3 objetivos gerais identificados ao analisarmos o foco das disciplinas de outras instituições. Isso indicou tanto que os objetivos das disciplinas analisadas são relevantes e que há um reconhecimento explícito dessa relevância, quanto que nossos e nossas discentes possuem diferentes necessidades com relação a esses três objetivos gerais. Embora focassem em um ou dois, nenhuma das disciplinas analisadas contemplava os três objetivos.

As respostas também ofereceram informações úteis sobre como uma disciplina introdutória deveria ser conduzida. Contextualizar conteúdos e atividades em situações interessantes e que façam sentido para os/as discentes é importante para favorecer o interesse e promover o entendimento. Oferecer uma apresentação do próprio curso e uma visão em largura da Computação, suas subáreas, possibilidades de atuação profissional, é útil para situar discentes no curso que estão iniciando e para oferecer perspectivas de atuação. Ao mesmo tempo em que há uma necessidade de se aprender a "pensar computacionalmente" independentemente de linguagem de programação e do próprio computador, há também a necessidade motivacional de engajar discentes desde cedo em atividades práticas nas quais possam ver seu progresso e possibilidades de aprendizado com contribuição efetiva.

\subsection{Nosso Conjunto de 17 Habilidades}

Com o levantamento realizado na seção anterior, compilamos um conjunto de habilidades consideradas essenciais para serem exercitadas desde o início do curso de graduação em Ciência da Computação da UFPR. Esse conjunto de habilidades reflete nosso entendimento e realidade, sendo naturalmente influenciado pelos contextos pessoais e profissionais onde atuamos. Portanto, o conjunto de habilidades apresentado não é exaustivo, muito menos universal ou definitivo. É um conjunto base que pode (e deve) ser revisitado no decorrer do tempo e de acordo com o contexto e a realidade da educação em seu sentido mais amplo. 
Tabela 1: Conjunto das 17 habilidades selecionadas.

\begin{tabular}{|c|c|c|c|}
\hline & Habilidade & Descrição & Ref. \\
\hline 1. & Abstração & $\begin{array}{l}\text { Habilidade de filtrar dados e informação, e sua classificação, ignorando elementos que não são necessários } \\
\text { para se concentrar naqueles que são relevantes. }\end{array}$ & [25][26] \\
\hline 2. & Decomposição & Habilidade de dividir problemas em partes menores para análise, entendimento e resolução. & [25] \\
\hline 3. & $\begin{array}{l}\text { Reconhecimento de } \\
\text { Padrões }\end{array}$ & $\begin{array}{l}\text { Habilidade de identificar similaridades ou características que problemas compartilham e que podem ser } \\
\text { exploradas para que sejam solucionados de forma mais eficiente. }\end{array}$ & [26][20] \\
\hline 4. & Algoritmos & $\begin{array}{l}\text { Capacidade de criar um plano, estratégia ou conjunto de instruções claras necessárias para a solução de um } \\
\text { problema; resolver problemas que tenham solução algorítmica e entender os limites da computação. }\end{array}$ & [26][15] \\
\hline 5. & Depuração/Revisão & $\begin{array}{l}\text { Capacidade de analisar o conjunto de instruções de uma solução, entender seu funcionamento, identificar } \\
\text { problemas e possíveis melhorias. }\end{array}$ & {$[26][20]$} \\
\hline 6. & Eficiência & Capacidade de criar e aprimorar soluções da melhor forma possível ou viável. & [26][20] \\
\hline 7. & Leitura & $\begin{array}{l}\text { Capacidade de leitura e interpretação de textos técnicos e acadêmicos, em português e em inglês; capacidade } \\
\text { de entender diagramas, modelos e códigos desenvolvidos por outras pessoas. }\end{array}$ & {$[26][10]$} \\
\hline 8. & Escrita & $\begin{array}{l}\text { Habilidade de expressão escrita, de forma precisa e fundamentada, tanto das soluções quanto de ideias, } \\
\text { discussões, relatórios técnicos, etc., para diferentes audiências. }\end{array}$ & {$[13][26]$} \\
\hline 9. & Síntese & $\begin{array}{l}\text { Capacidade de sumarizar conteúdos, esquemas, ideias, códigos, produzindo algo como resultado que resuma, } \\
\text { estenda ou aperfeiçoe o que já existe. }\end{array}$ & [12] \\
\hline 10. & Autonomia & $\begin{array}{l}\text { Comprometimento com o aprendizado continuado e independente, sendo capaz de acompanhar a evolução } \\
\text { da área; capacidade de investigar e conduzir atividades, produzindo resultados além do solicitado. Estudantes } \\
\text { precisam exercitar sua capacidade de organização, gerenciamento de tempo, progresso e prioridades. }\end{array}$ & [26][23] \\
\hline 11. & Colaboração & Habilidade de unir esforços com outras pessoas para o desenvolvimento de atividades. & {$[26][10]$} \\
\hline 12. & Rigor & $\begin{array}{l}\text { Capacidade de desenvolver trabalhos e atividades dentro do prazo, contemplando todos os requisitos } \\
\text { solicitados e apresentando informações e resultados de forma não ambígua. }\end{array}$ & {$[26][20]$} \\
\hline 13. & $\begin{array}{l}\text { Ética e Responsabilidade } \\
\text { Profissional }\end{array}$ & $\begin{array}{l}\text { Habilidade de desenvolver ações e soluções de forma socialmente responsável, atenta às possíveis implicações } \\
\text { e efeitos no mundo, incluindo as questões sociais, legais, éticas e culturais inerentes à disciplina. }\end{array}$ & {$[13][26]$} \\
\hline 14. & Experiência de Projetos & $\begin{array}{l}\text { Estudantes devem desenvolver habilidades de condução e participação em projetos integrativos, que exijam } \\
\text { a avaliação de soluções potenciais e promovam o exercício da comunicação interpessoal. }\end{array}$ & {$[13][26]$} \\
\hline 15. & Visão Sistêmica & $\begin{array}{l}\text { Habilidade de pensar em vários níveis de detalhes e abstração, buscando a apreciação da estrutura de } \\
\text { sistemas e processos, e suas interações com a realidade, incluindo o entendimento do contexto em que o } \\
\text { sistema computacional funcionará e suas interações com as pessoas e o mundo físico. Essa habilidade inclui } \\
\text { desenvolver a consciência sobre a ampla aplicabilidade da Computação. }\end{array}$ & [13] \\
\hline 16. & Resolução de Problemas & $\begin{array}{l}\text { Habilidade de entender como desenvolver e aplicar o conhecimento técnico para resolver problemas reais, } \\
\text { reconhecendo a possibilidade de múltiplas soluções para um mesmo problema e que a escolha da solução } \\
\text { deve considerar, além das questões técnicas, o seu impacto na vida de outras pessoas. }\end{array}$ & {$[13][26]$} \\
\hline 17. & $\begin{array}{l}\text { Conhecimento do } \\
\text { Domínio }\end{array}$ & $\begin{array}{l}\text { Capacidade de entender que a Computação interage com domínios diferentes e que alguns problemas reque- } \\
\text { rem conhecimento de domínios específicos; estudantes devem entender e serem capazes de se comunicar e } \\
\text { aprender com especialistas de diferentes áreas. }\end{array}$ & {$[13][26]$} \\
\hline
\end{tabular}

O conjunto apresentado na Tabela 1 possui relação direta com as habilidades do Pensamento Computacional [25] e com aquelas descritas nas recomendações de currículo da SBC [26] e da ACM e IEEE [13], incluindo as chamadas soft skills que, em nosso entendimento, são as habilidades mais desafiadoras de serem trabalhadas por dependerem fortemente do método didático empregado. A ordem das habilidades não designa importância ou hierarquia.

As habilidades de 1 a 9 são habilidades básicas essenciais para a solução de problemas computacionais; as habilidades de 10 a 14 são habilidades de comportamento profissional e responsabilidade; e as habilidades de 15 a 17 são habilidades fortemente relacionadas a solução de problemas reais e complexos.

Especificamente sobre as habilidades para a solução de problemas computacionais, desenvolver a capacidade de abstração é essencial para as demais habilidades de estudantes de Computação nas mais diversas atividades profissionais, em especial para a competência em construir algoritmos e programar. A construção de algoritmos, por sua vez, engloba outras habilidades específicas e algumas delas são especialmente importantes para o desenvolvimento de habilidades de programação: Representação - habilidade de representar uma solução para um problema utilizando alguma linguagem (natural, fluxograma, programação); Legibilidade - habilidade de representar soluções de forma que seja de fácil entendimento por outras pessoas, seja um código, um fluxograma ou um conjunto de instruções em linguagem natural; Fluxo de controle - habilidade de estruturar as instruções em ordem coerente para resolver um problema; Condição - habilidade de aplicar, de forma correta e pertinente, estruturas de condição em uma sequência de instruções; e Repetição - habilidade 
de aplicar, de forma correta e pertinente, estruturas de repetição em uma sequência de instruções.

\section{ESTRUTURA DA DISCIPLINA}

Com base no levantamento apresentado na seção anterior, a disciplina de ICC foi criada para promover o exercício das habilidades que consideramos importantes para os/as estudantes no primeiro semestre do nosso curso de Ciência da Computação. A Figura 1 apresenta a ementa e os objetivos da disciplina.

\begin{tabular}{|l|l|l|}
\hline \multicolumn{2}{|l|}{ Disciplina: Introdução à Ciência da Computação } & Código: ICC \\
\hline Natureza: (x) Obrigatória ( ) Optativa & Carga horária total: $60 \mathrm{~h}$ \\
\hline Período: $1^{o}$ Semestre & \multicolumn{2}{|c|}{ Carga horária semanal: $4 \mathrm{~h}$} \\
\hline
\end{tabular}

Ementa: Introdução à Ciência da Computação. O que é Ciência da Computação? História da Computação; Impactos da Computação na ciência, tecnologia e sociedade; Áreas da Ciência da Computação; O curso de Ciência da Computação; Pensamento computacional. O que é pensamento computacional? Entendimento e resolução de problemas utilizando técnicas de pensamento computacional; Noção de algoritmos; Atuação profissional em Computação; Pensamento sistêmico e socialmente consciente: teoria e prática; Possibilidades e demandas do mercado de trabalho; Características esperadas de um profissional de Ciência da Computação.

Objetivo Geral: Favorecer o pensamento computacional, crítico e sistêmico de estudantes sobre a Ciência da Computação e suas possibilidades de atuação.

\section{Objetivos Específicos:}

(1) Conhecer as principais áreas da Ciência da Computação;

(2) Familiarizar-se com a Grade Curricular do curso e suas diferentes disciplinas;

(3) Vislumbrar a área de Computação e possibilidades de atuação;

(4) Exercitar o pensamento abstrato;

(5) Exercitar a capacidade de interpretação e análise de problemas de forma crítica;

(6) Exercitar o pensamento algorítmico independente de linguagem de programação;

(7) Refletir sobre aspectos éticos e sociais de forma contextualizada e transversal à Computação e suas áreas;

(8) Experimentar diferentes ferramentas e recursos de apoio ao aprendizado;

(9) Desenvolver a autonomia no trabalho individual e em equipes;

(10) Desenvolver habilidades de comunicação oral e escrita.

Figura 1: Ementa da disciplina de ICC.

Procedimentos didáticos: como as habilidades que apresentamos e os objetivos da disciplina indicam, o método didático empregado é chave para esta disciplina. Há habilidades que dependem da experiência de trabalho em equipes, resolvendo problemas relevantes para o contexto social em que o curso, estudantes e professores se situam. Para promover o exercício das habilidades e para alcançar os objetivos da disciplina, o método didático trabalha a disciplina em 3 eixos, adotando uma perspectiva crítica e participativa, com dinâmicas e procedimentos distintos e adequados a cada eixo. A dinâmica é inspirada pelo Método Paulo Freire [4] em suas etapas de investigação, tematização e problematização, adicionando etapas de socialização dos resultados produzidos.

Eixo 1. Introdução à Ciência da Computação: com duração estimada de 14 horas, os tópicos podem ser apresentados em aulas expositivas com atividades pontuais para promover a participação discente. A dinâmica deve ser influenciada pela proposta de sala de aula invertida [22][10], de modo que estudantes tenham acesso a leituras e materiais selecionados para cobrir questões importantes tanto do histórico quanto de personagens importantes da Computação, e de aplicações e implicações da Computação na sociedade. É importante que as pessoas se engajem em discussões e tragam exemplos e questões para o debate.

Eixo 2. Pensamento Computacional: com duração estimada de 22 horas, os tópicos devem ser apresentados e discutidos de forma expositiva e argumentativa e trabalhados em atividades práticas em uma abordagem orientada à resolução de problemas, sem o uso obrigatório de uma linguagem de programação. Durante essas aulas, a habilidade de interpretar problemas será exercitada, com uma solução sendo proposta e executada em atividades colaborativas. Quando possível, devem ser usados recursos físicos (papel e caneta, objetos, etc.) - i.e., computação "desplugada"[2] - e práticas de trabalho em equipes. Quando a interação presencial não for possível, dinâmicas mediadas por ferramentas colaborativas podem ser empregadas, mas sem exigir a utilização de uma linguagem de programação. As propostas de resolução devem ser estruturadas e representadas em alguma forma de linguagem natural (e.g., descrição de ações, passo-a-passo, fluxograma, etc.), para que seja possível analisar e comparar diferentes soluções e diferentes formas de representá-las.

Eixo 3. Pensamento Sistêmico e Socialmente Consciente: com duração estimada de 24 horas, devem ser adotadas atividades práticas colaborativas com o objetivo de propor, prototipar e avaliar um sistema computacional interativo. O sistema proposto deverá resolver um problema ou apoiar uma atividade em um contexto social relevante (e.g., utilizar problemas relacionados aos Objetivos do Desenvolvimento Sustentável da $\mathrm{ONU}^{3}$ ). Para isso, devem ser conduzidas atividades práticas de brainstorming e planejamento, atividades de laboratório para a modelagem, prototipação e avaliação da solução proposta e práticas de socialização dos resultados.

A prototipação é o procedimento didático recomendado para apoiar a materialização das ideias. Com um protótipo produzido ${ }^{4}$, estudantes podem investigar aspectos relevantes de diversas áreas da Computação que serão necessários para transformar o protótipo em um sistema computacional interativo usável. As pessoas podem discutir áreas como Banco de Dados, Sistemas Operacionais e Algoritmos, por exemplo, de forma instanciada no contexto da solução prototipada. Com um protótipo, também se torna mais concreto pensar e discutir os possíveis impactos das soluções propostas, não apenas técnicos mas, principalmente, sociais, podendo inclusive envolver outras partes interessadas na análise e avaliação do protótipo. Os resultados devem ser socializados na forma de seminários interativos, servindo como base para ilustrar as possíveis

\footnotetext{
${ }^{3}$ https://brasil.un.org/pt-br/sdgs último acesso em 24 de outubro de 2020

${ }^{4} \mathrm{O}$ nível de fidelidade ou sofisticação do protótipo desenvolvido não deve ser rígido: estudantes devem poder criar protótipos de baixa fidelidade em papel, wireframes e storyboards interativos, ou mesmo criar protótipos funcionais codificando as soluções ou aplicando algum framework ou engine de apoio.
} 
atuações de profissionais de Computação, com destaque para sua responsabilidade ética e social.

Formas de avaliação: a avaliação do trabalho discente deve considerar os resultados da participação individual e em equipes. $\mathrm{Na}$ Participação Individual, devem ser consideradas todas as entregas de atividade que atendam aos requisitos solicitados e ocorram dentro do prazo estipulado. Recomendamos que o foco esteja no compromisso da entrega pontual atendendo aos requisitos solicitados mais do que no desempenho propriamente dito. Considerando a diversidade de formação prévia do corpo discente, consideramos que o ponto mais importante seja o comprometimento com suas atividades individuais. Assim, buscamos fazer com que as experiências sejam vividas ao longo da disciplina de modo que cada discente possa avançar em seu próprio aprendizado. Na Participação em Equipes, o foco está na Qualidade do Projeto, englobando o atendimento aos prazos de entrega, completude, qualidade do conteúdo e da forma do projeto entregue e de sua apresentação. Aqui, entendemos ser importante considerar também como a equipe se organizou e gerenciou suas atividades, além da criatividade e potencial do projeto desenvolvido. Os critérios ou pontos de avaliação devem ser adequados ao projeto (problema e solução) escolhido. Finalmente, consideramos que a autoavaliação sobre as atividades conduzidas, o aprendizado e a dedicação à disciplina são importantes e necessários para promover a reflexão discente sobre sua atuação, e para oferecer aos docentes informações adicionais sobre a perspectiva e o contexto discente.

\section{ICC REMOTA}

A disciplina de ICC foi oferecida presencialmente nos dois semestres de 2019. Em 2020, oferecemos a disciplina no formato remoto devido à pandemia causada pela COVID-19. Para isso, ajustamos o conteúdo programático de modo a atender requisitos específicos para o período, especialmente considerando as características do público discente e o ambiente remoto.

Oferecemos a disciplina ICC Remota com suas 60 horas distribuídas em um período de 5 semanas (agosto a setembro), com 20 horas de aulas síncronas e 40 horas assíncronas com todas as atividades e materiais previamente disponibilizados e apresentados. Um total de 54 discentes se matricularam nas 3 turmas oferecidas, sendo que 50 discentes chegaram a frequentar pelo menos uma aula síncrona e 46 discentes finalizaram a disciplina. Do total de 50 discentes que participaram de pelo menos uma aula, 39 (78\%) eram do gênero masculino e 11 feminino (22\%). As 3 turmas foram trabalhadas em conjunto por 3 docentes responsáveis (os 3 autores), com o apoio de 3 discentes de pós-graduação (1 de mestrado, 2 de doutorado) fazendo estágio de docência na disciplina.

Adotamos a dinâmica de sala de aula invertida de forma intensificada, com atendimentos de dúvidas realizados sob demanda ao longo de todo o período. Como recursos de apoio e gerenciamento da disciplina utilizamos o sistema Moodle, para as aulas síncronas (e sua gravação) o sistema BigBlueButton, e para o atendimento de dúvidas utilizamos fóruns online, e-mails e um grupo no WhatsApp. Outros sistemas foram utilizados como apoio para atividades específicas, como o MarvelApp para prototipação, o Padlet para quadros e dinâmicas colaborativas, o YouTube para a disponibilização de vídeos produzidos por discentes e um sistema Wiki para a edição colaborativa de textos. Além disso, para promover o engajamento discente no Moodle, o recurso de Emblemas foi habilitado com um conjunto de 12 emblemas vinculados à realização de atividades, e quatro jogos interativos foram disponibilizados para o exercício e assimilação de conteúdos. Os jogos foram: Forca, Show do Milionário - inspirado no famoso Show do Milhão, Quiz - com questões criadas por docentes e discentes, e Quiz Venture - um jogo no estilo space invader em que é preciso controlar uma nave atirando contra as naves inimigas que possuem a resposta correta para determinada questão.

\subsection{Programa de ICC Remota}

A carga horária da disciplina foi desenvolvida de forma equilibrada entre as 5 semanas, com aproximadamente 12 horas por semana (exceto a segunda e a quinta semanas com 10 e 14 horas, respectivamente). Os conteúdos foram agrupados em 3 blocos, cada um cobrindo um eixo da disciplina e envolvendo uma ou mais entregas.

Na sequência, listamos o objetivo, os tópicos trabalhados do programa da disciplina, com suas estratégias didáticas e suas cargas horárias $(\mathrm{CH})$, e as entregas avaliativas solicitadas para o bloco.

Bloco 1: Introdução à Ciência da Computação (03/08 a 07/08). O objetivo deste bloco é promover o entendimento da área de Computação e do curso escolhido, de modo que os/as discentes conheçam não apenas a Computação com alguns de seus marcos e personagens, mas também tenham uma visão do curso, seus docentes, entendam as disciplinas que cursarão e suas relações com o perfil profissional do curso.

1. Orientações sobre a disciplina remota; Apresentação da agenda, dos critérios e da dinâmica da disciplina. Estratégia: apresentação e conversação online síncrona via Ferramenta de videoconferência. $\mathrm{CH}: 2$ horas.

2. Estudo sobre a Computação e suas áreas; Estudo sobre o curso de Computação, suas disciplinas e professores. Estratégia: Investigação utilizando o website do departamento e do curso; leitura dos materiais disponibilizados no Moodle (artigos, livros e websites). $\mathrm{CH}$ : 6 horas.

3. Marcos históricos da Computação, com áreas e pessoas pioneiras. Estratégia: investigação na Internet e nos materiais indicados, com apoio de um fórum para a discussão e recursos de bate-papo síncrono. $\mathrm{CH}$ : 2 horas.

4. Currículo referência da ACM e IEEE [13] e perfil do profissional da Computação. Estratégia: leitura e discussão do currículo referência, áreas e habilidades esperadas. $\mathrm{CH}$ : 2 horas.

O Bloco 1 possui ênfase na leitura de diferentes textos, tanto em português quanto em inglês, que abordam questões relevantes da Computação, seu histórico, aspectos técnicos e filosóficos, questões de currículo e questões sociais. Estas leituras demandam autonomia e capacidade de organização de tempo, de foco, de interpretação. Como entrega para o Bloco 1, cada estudante deveria escolher 1 dentre 43 tópicos representando áreas e temas importantes da Computação (de Teoria dos Grafos a Informática na Educação) e desenvolver uma página Wiki para o tópico selecionado. Como o número de estudantes era superior ao número de tópicos, cada tópico poderia ser trabalhado por até duas pessoas de forma colaborativa; neste caso, o recurso de histórico de edições da Wiki era 
utilizado como forma de identificar as contribuições individuais e as diferentes versões de uma página.

Como conteúdo, cada página deveria apresentar pelo menos: Título (nome do tópico) e autoria; I. Visão geral: o que é? sobre o que trata? para que serve? II. Principais marcos da evolução do tópico: desde a sua criação até o cenário atual. III. Grandes Nomes (ao menos 2) no cenário internacional e nacional (contemplar nomes de mulheres), e ao menos um nome de docente do departamento que atua na área ou em área relacionada; deveria ser apresentada uma biografia curta sobre a atuação e contribuição de cada nome. IV. Aplicações e Impacto Social: exemplos práticos de aplicações na área, casos reais, etc. V. Desafios: desafios atuais de pesquisa e desenvolvimento na área. VI. Referências. Além disso, cada estudante deveria criar 2 questões para serem respondidas sobre o conteúdo elaborado. A entrega para o Bloco 1 adota a escrita como forma de organizar as ideias e saber como comunicá-las a outras pessoas; o bloco cobre 6 dos 10 objetivos específicos da disciplina.

Bloco 2: Pensamento Computacional (10/08 a 21/08). O objetivo deste bloco é promover habilidades de entendimento e resolução de problemas exercitando habilidades de pensamento computacional e noções de algoritmos independente de uma linguagem de programação. Ainda, promovemos discussões sobre questões éticas na profissão. Neste bloco, utilizamos um conjunto de 4 desafios para exercitar diferentes habilidades do Pensamento Computacional.

5. Leitura de artigo sobre Pensamento Computacional [25]. Estratégia: leitura e discussão em fórum. $\mathrm{CH}$ : 2 horas.

6. Conversação: discussões sobre as leituras. Estratégia: apresentação e discussão por videoconferência. $\mathrm{CH}: 2$ horas.

7. Desafio 1. Raciocínio. Dois exercícios de raciocínio que exigem a interpretação de dicas e instruções foram conduzidos. Estratégia: 1. "O mais velho tem olhos azuis", um desafio para descobrir a idade dos filhos de uma pessoa seguindo um conjunto de dicas; e 2. "Desafio dos Laboratórios", um desafio adaptado em que, seguindo um conjunto de regras, é preciso descobrir quais professores ocupam quais laboratórios, programam em linguagens de programação específicas e indicam determinados livros. $\mathrm{CH}$ : 3 horas.

8. Desafio 2. Criptografia: uma mensagem que deve ser descriptografada para que se possa entender seu conteúdo. Estratégia: cada discente deve resolver o desafio individualmente explicando como descriptografou a mensagem (usando um conjunto de passos, infográfico ou fluxograma) e registrar o tempo gasto para resolver o desafio. $\mathrm{CH}: 3$ horas.

9. Desafio 3. Problema da Ordenação [19]: consiste em ordenar, por diferentes critérios (e.g., nome, data de nascimento, área, etc.) um conjunto de cartões que apresentam diferentes pessoas relevantes para a história da Computação. Estratégia: individualmente, cada discente deve propor uma forma de ordenar um conjunto de n cartões, representar, na forma de passos ou fluxograma, uma sequência de ações para ordenar os cartões e indicar a quantidade de passos necessários. $\mathrm{CH}$ : 4 horas.

10. Desafio 4. Problema da Celebridade [19]: propor uma forma de identificar se existe ou não uma celebridade em uma festa com $n$ pessoas. Estratégia: cada discente deve elaborar uma sequência de ações para identificar se existe uma celebridade na festa (se existir, deve nomeá-la; se não existir, deve informar que não há) e então representar a sequência de ações na forma de fluxograma, indicando quantas perguntas são necessárias para encontrar a celebridade ou concluir que não há nenhuma. $\mathrm{CH}$ : 4 horas.

11. Conversação: discussões sobre os quatro desafios trabalhados. Estratégia: visão geral sobre os resultados dos desafios, apresentação e discussão por videoconferência. $\mathrm{CH}$ : 2 horas.

12. O Caso do Robô Assassino: este item apresenta um conjunto de matérias que revelam os desdobramentos de um caso hipotético em que um operador morreu ao operar um robô. $\mathrm{O}$ caso foi criado por [7], da Universidade Westchester da Pensilvânia, e cobre aspectos éticos do processo de desenvolvimento de software. Com base nas leituras das matérias sobre o caso, cada discente deve elaborar um texto em formato livre discorrendo sobre a noção de responsabilidade dos profissionais envolvidos no desenvolvimento de sistemas computacionais. $\mathrm{CH}$ : 4 horas.

13. Conversação: discussão sobre responsabilidade ética e o caso do robô. Estratégia: o caso do robô, o dilema do trem e o caso real de uma morte causada por um carro automático em 2018, foram utilizados como cenário de discussão síncrona, com enquetes e nuvens de palavras criadas dinamicamente. $\mathrm{CH}$ : 2 horas.

Como entregas para o Bloco 2, cada estudante deveria resolver os Desafios (1 a 4) e elaborar o texto sobre o Caso do Robô. Todas as entregas eram feitas em um fórum específico. No Desafio 4, após a sua resolução, cada discente deveria analisar e avaliar uma solução desenvolvida por outra pessoa, ajudando a melhorá-la. A análise deveria cobrir questões de desempenho (quantidade de perguntas necessárias), corretude da solução e legibilidade.

Bloco 3: Pensamento Sistêmico e Socialmente Consciente (24/08 a 04/09). O objetivo deste bloco é exercitar habilidades de entendimento do problema, de proposta de uma solução e, na apresentação desta proposta, relacioná-la com as diferentes áreas da Computação.

O Bloco 3 utilizou como contexto o Objetivo de Desenvolvimento Sustentável \#5 da Organização das Nações Unidas "Igualdade de Gênero", especialmente a meta 5.b.: Aumentar o uso de tecnologias de base, em particular as tecnologias de informação e comunicação, para promover o empoderamento das mulheres. Portanto, o Bloco 3 vai além do entendimento e resolução de problema, abordando um tema de importância crítica tanto no cenário nacional quanto internacional. A responsabilidade profissional e as questões éticas são transversais a todas as ações: de escolher o problema até considerar os possíveis impactos de uma solução prospectiva.

Em equipes de até 6 pessoas, cada equipe trabalhou em um processo inspirado no método de Design Thinking [5], passando pelos estágios de Empatia, Definição, Ideação, Prototipação, Teste, Videodemo, e autoavaliação (por discente).

14. Empatia e definição. Utilizando materiais disponibilizados e pesquisas com dados e estatísticas sobre o tema, cada equipe deve responder: Por que é importante abordar esse objetivo? Estratégia: cada equipe deve reunir e discutir o entendimento sobre o tema e escolher um problema específico para trabalhar, respondendo: no contexto do Objetivo \#5, qual problema tentaremos ajudar a resolver por meio de uma solução computacional? $\mathrm{CH}$ : 2 horas.

15. Ideação. Com o problema definido, cada equipe deve gerar ideias para resolver seu problema. Estratégia: cada equipe deve: i) levantar várias soluções possíveis; ii) discutir os prós e contras de cada uma; iii) e escolher a mais interessante (promissora, inovadora, etc.); cada equipe deve responder: Qual será a nossa solução computacional para o problema levantado? $\mathrm{CH}: 2$ horas. 
16. Prototipação. Criação de um protótipo para a solução proposta. Estratégia: utilizando alguma ferramenta online de prototipação (ou tirando fotos de protótipos manuais, cartões, etc.), cada equipe deve apresentar um protótipo da solução para o problema levantado e deve descrever essa solução explicando o que ela faz e o quão boa ela deve ser. $\mathrm{CH}: 2$ horas.

17. Testes. Avaliar a qualidade geral do protótipo criado e seu possível impacto. Estratégia: com o protótipo elaborado, cada equipe deve fazer testes e avaliações com outras pessoas, pedindo-as para explorar o protótipo e fornecer opiniões. $\mathrm{CH}: 2$ horas.

18. Estudo das áreas da Computação. Utilizando o protótipo como contexto, cada estudante deve estudar e investigar os conhecimentos e habilidades necessárias para transformar o protótipo em produto. Estratégia: com o protótipo construído, cada participante da equipe deve selecionar um tópico dentre aqueles trabalhados no Bloco 1, e investigar como aquele tópico deve ser estudado e aplicado para a evolução do protótipo na direção de uma solução computacional efetiva. $\mathrm{CH}$ : 4 horas.

19. Produção do material de apresentação. Apresentação da equipe, do problema e da solução. Estratégia: cada equipe deve desenvolver um videodemo de até 5 minutos cobrindo: I. Apresentação da equipe; II. O problema abordado; III. A solução proposta e seu protótipo; IV. As áreas da Computação que serão necessárias para evoluir do protótipo para a solução final (pelo menos uma área por integrante da equipe) e os conhecimentos e habilidades envolvidos. $\mathrm{CH}$ : 6 horas.

20. Conversação: socialização, discussão e presentação prévia das soluções. Estratégia: as equipes devem apresentar seus problemas e ideias, e receber dicas para a elaboração do projeto e questionamentos para refletir sobre a solução pensada para o problema proposto e seus impactos. $\mathrm{CH}: 2$ horas.

Durante uma semana, cada item de 14 a 17, foi apoiado por um encontro síncrono com docentes da disciplina para discussão e troca de ideias. Em cada encontro, os docentes conduziam a discussão aplicando alguma técnica alinhada ao Design Thinking [5]. Por exemplo, o Mapa da Empatia [8] para o entendimento e definição, a técnica The Worst Possible Idea [17] para a ideação, ferramentas Cacoo e MarvelApp para a criação de Storyboards [24] e prototipação, e a técnica Thinking Aloud [3] para a avaliação. A participação nesses encontros era opcional e, por recomendação dos docentes, cada equipe se organizou para ter pelo menos uma pessoa participando em cada encontro de modo a disseminar a experiência aos demais.

O Bloco 3 cobre 8 dos 10 objetivos específicos da disciplina, e exercita habilidades de leitura, escrita, autonomia, colaboração, responsabilidade, entre outras, se estendendo também para as questões éticas e de valores humanos [16]. Com o tema selecionado, o bloco discute um objetivo do desenvolvimento sustentável que está relacionado à baixa participação de mulheres nos cursos de Computação. Como entregas para o Bloco 3, cada equipe deveria compartilhar uma mensagem no fórum de projetos registrando as entregas de cada fase publicamente e, ao final, entregar um videodemo e as autoavaliações de cada participante. A pontualidade, completude, qualidade do conteúdo e qualidade da forma foram utilizadas como parâmetros para a avaliação. Porém, a autoavaliação discente acabou tendo grande influência nas notas finais, sendo utilizada em boa parte para elevar as notas. Para a autoavaliação, cada participante deveria criar uma resposta pública no tópico de entrega da equipe explicando as atividades que desenvolveu no Bloco 3 e atribuindo a si uma nota de 0 a 100 pela própria dedicação, colaboração e qualidade do trabalho realizado.

\section{RESULTADOS E DISCUSSÕES}

De 50 discentes que participaram de pelo menos uma atividade, 4 desistiram antes da realização do Bloco 3 e 46 discentes finalizaram o curso com aprovação. Não houve reprovação para discente que tenha desenvolvido todas as atividades propostas. A média para aprovação no curso é de 50 pontos e a média de notas da disciplina foi de 91,5 pontos. Um questionário online e anônimo foi aplicado após a finalização da disciplina para obter o retorno discente sobre a disciplina, com sua dinâmica, conteúdos e recursos. De 46 discentes que finalizaram a disciplina, 29 (63\%) responderam o questionário. Das 29 respostas, identificamos uma que consideramos ser um outlier por estar no extremo negativo em todas as respostas sobre a disciplina e não deixar explicação ou comentário que pudéssemos entender o porquê das classificações negativas. Consideramos, portanto, 28 respostas válidas ( $60,8 \%$ do total de discentes).

Considerando as 28 respostas válidas recebidas, a faixa de idade variou de 17 a 33 anos, sendo que 75\% (21) possuem entre 17 e 19 anos. Sobre os dispositivos utilizados para as aulas, $22(78,5 \%)$ discentes utilizavam notebook, $8(28,5 \%)$ utilizavam computador desktop, 14 (50\%) utilizavam celular, e $3(10,7 \%)$ utilizavam tablet. Sobre a qualidade da conexão com a Internet, em uma escala de 1 a 10 , $26(92,8 \%)$ classificaram como 6 ou superior, e $2(7,1 \%)$ discentes classificaram a qualidade como abaixo de 5 pontos. A disponibilidade de equipamentos e a boa conexão com a Internet eram esperadas pois a matrícula para ICC Remota era opcional. Os alunos teriam a matrícula garantida na disciplina presencial quando o calendário fosse retomado presencialmente.

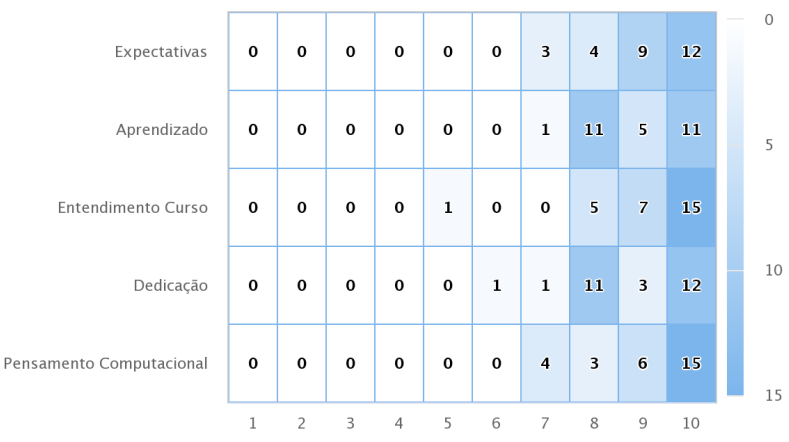

Figura 2: Percepção sobre cursar a disciplina.

A Figura 2 sumariza as respostas para 5 questões, mostrando a predominância de respostas entre 8 e 10 para todas elas. Sobre as Expectativas para a disciplina, em uma escala de 1 (Foi pior do que eu esperava) a 10 (Foi melhor do que eu esperava), 25 (89,2\%) pessoas indicaram 8 ou mais, mostrando que a forma como a disciplina foi trabalhada na versão remota superou as expectativas discentes. Esses resultados não nos permitem dizer que nossa proposta foi considerada excelente, mas que conseguimos superar as expectativas que nossos alunos e alunas tinham para uma versão remota da disciplina no período atual. 
Sobre a percepção de Aprendizado com a disciplina, em uma escala de 1 (Não aprendi nada) a 10 (Aprendi muito), 27 (96,4\%) pessoas indicaram 8 ou mais, mostrando uma autopercepção discente fortemente positiva sobre o aprendizado desenvolvido na disciplina. Por ser uma disciplina de primeiro semestre, em um período ainda mais desafiador que o comum, entendemos que a autopercepção de aprendizado seja fundamental para a motivação, interesse e envolvimento discente no curso. Considerando o propósito que temos com essa disciplina no primeiro semestre, e reconhecendo nossas limitações em conhecer a realidade e os conhecimentos de base que discentes ingressantes trazem para o curso, entendemos que a autopercepção dos alunos e alunas sobre seu próprio progresso é mais importante do que a nossa percepção sobre esse progresso.

Sobre a disciplina ajudar no Entendimento sobre o Curso, em uma escala de 1 (Não ajudou em nada) a 10 (Ajudou muito), 27 $(96,4 \%)$ pessoas indicaram um valor de 8 ou mais, mostrando que a disciplina alcançou um de seus objetivos principais que é apresentar o curso de Computação. Novamente, aqui destacamos a importância de identificar a percepção discente sobre seu próprio entendimento, pois no início do curso a falta de clareza pode ter impactos negativos no envolvimento e progresso discente.

Sobre o nível de Dedicação da pessoa à disciplina, em uma escala de 1 (Não levei a sério) a 10 (Me dediquei ao máximo), 26 (92,8\%) respostas indicaram 8 ou mais, uma resposta indicou 6 e outra indicou 7. E sobre as habilidades do Pensamento Computacional, em uma escala de 1 (Não exercitei nada) a 10 (Exercitei muito), 24 (85,7\%) pessoas indicaram 8 ou mais, indicando que a abordagem baseada em desafios que utilizamos, inspirada na pesquisa de [19], foi capaz de chamar a atenção para as habilidades do Pensamento Computacional e promover seu exercício de acordo com o entendimento discente sobre essas habilidades.

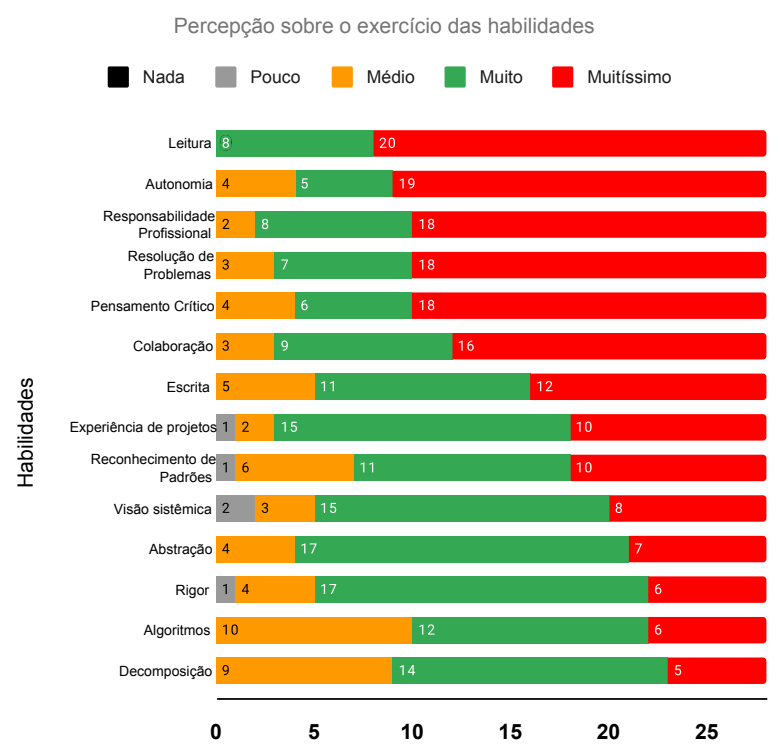

Figura 3: Percepção sobre as habilidades exercitadas.
Focando no conjunto de habilidades que pretendemos exercitar com toda a disciplina, seus conteúdos, atividades e o método empregado, perguntamos: "Na disciplina como um todo, o quanto você considera ter exercitado de cada habilidade", aceitando como resposta 5 opções (Nada, Pouco, Médio, Muito, Muitíssimo) - vide Figura 3. As respostas indicam uma tendência de percepção positiva para todas elas. Por exemplo, considerando 28 respostas, $25(89,2 \%)$ consideram que exercitaram Muito (7) ou Muitíssimo (18) a habilidade de Resolução de Problemas. Como habilidades relacionadas: Abstração - 24 (85,7\%) consideram que exercitaram Muito (17) ou Muitíssimo (7); Algoritmos - 18 (64,2\%) exercitaram Muito (12) ou Muitíssimo (6); Decomposição - 19 (67,8\%) consideram que exercitaram Muito (14) ou Muitíssimo (5); e Reconhecimento de Padrões - $21(75 \%)$ consideram que exercitaram Muito (10) ou Muitíssimo (11). Essas respostas indicam que a percepção discente é de que as habilidades de resolução de problemas foram muito exercitadas na disciplina, atendendo aos nossos objetivos.

Outras duas habilidades que buscamos promover com a disciplina são a leitura de livros, artigos e matérias relevantes e diversificadas e a capacidade de expressão escrita. Mais de 30 materiais foram disponibilizados para leitura, de variados temas como Ética em algoritmos [18], história das mulheres na Computação [21] e relação da Computação com a Matemática [14], entre outros textos como [11] [9] [6]. Para a escrita, além do texto para a página Wiki, cada entrega exigia explicações e justificativas sobre o trabalho desenvolvido, exercitando a habilidade de síntese e a capacidade de expressão escrita. Enquanto $23(82,1 \%)$ pessoas consideram ter exercitado Muito (11) ou Muitíssimo (12) a habilidade de Escrita, 28 $(100 \%)$ pessoas consideram ter exercitado Muito (8) ou Muitíssimo (20) a habilidade de Leitura.

Outras duas habilidades que consideramos essenciais são a $\mathrm{Au}$ tonomia para o estudo e desenvolvimento de atividades e a Colaboração entre discentes. Ao todo, $24(85,7 \%)$ pessoas consideram ter exercitado Muito (5) ou Muitíssimo (19) a Autonomia, enquanto 25 $(89,2 \%)$ pessoas consideram ter exercitado Muito (9) ou Muitíssimo (16) a Colaboração. Segundo os currículos da ACM e IEEE [13] e da SBC [26], essas são habilidades essenciais para a prática profissional, e consideramos que serão essenciais para o êxito no curso.

Considerando habilidades mais abrangentes, como a Experiência de projetos, o Pensamento Crítico, a Visão sistêmica e a Responsabilidade Profissional, as respostas também indicam que houve uma percepção positiva. Por exemplo, $25(89,2 \%)$ pessoas consideram ter exercitado Muito (15) ou Muitíssimo (10) a Experiência de projetos; 24 (85,7\%) pessoas consideram ter exercitado Muito (6) ou Muitíssimo (18) o Pensamento Crítico; 23 (82,1\%) pessoas consideram ter exercitado Muito (15) ou Muitíssimo (8) a Visão sistêmica; e 26 (92,8\%) pessoas consideram ter exercitado Muito (8) ou Muitíssimo (18) a Responsabilidade Profissional. Como a disciplina tem por objetivos o exercício de habilidades de projetos junto ao desenvolvimento da noção de responsabilidade profissional e da visão crítica, consideramos que esses objetivos foram alcançados de forma satisfatória.

Também utilizamos perguntas abertas, não obrigatórias, para obter informações qualitativas adicionais. Solicitamos que as pessoas pontuassem as dificuldades encontradas na disciplina, considerando principalmente o seu andamento no formato remoto. Ao todo, 19 
pessoas mencionaram algum tipo de dificuldade, sendo que a administração do tempo pessoal foi a mais mencionada (6 pessoas). Outras dificuldades estavam relacionadas a duração dos encontros síncronos de 2 horas, considerados longos, e a sua disposição em 5 semanas, considerada bastante concentrada. Apenas uma resposta indicou problema de conexão com a Internet e outra sobre o uso de diversas ferramentas até então desconhecidas. Finalmente, outra dificuldade mencionada foi a necessidade de maior autonomia e de capacidade de foco para a realização das atividades.

Para a questão "O que você mais gostou na disciplina?", recebemos 26 respostas que indicavam tanto questões didáticas quanto de conteúdo. A didática, de forma geral, foi indicada em 8 respostas como sendo um dos pontos mais apreciados, assim como as discussões desenvolvidas nos encontros síncronos, apontadas por 9 pessoas. A presença de mais que um docente nas discussões foi apreciada, assim como a possibilidade de ver as entregas das outras pessoas, a diversidade de tópicos e dinâmicas. $\mathrm{O}$ uso de emblemas, os desafios e as leituras foram apontados por 4 pessoas cada, enquanto os jogos e as atividades de escrita foram indicados por 3 pessoas e as atividades focadas nas discussões éticas por duas pessoas. As respostas nos indicam que a didática empregada foi positiva e capaz de promover o alcance dos objetivos.

Para a questão "O que você menos gostou na disciplina?"recebemos 19 respostas, sendo que 3 delas informaram não ter pontos que não gostaram. Das informações recebidas, o pouco tempo disponível para conseguir fazer as atividades foi o item mais citado, com 6 menções, seguido da alta quantidade de leituras ou textos longos, com 5 menções. Outras 3 respostas indicaram não ter gostado das aulas síncronas, sendo que uma foi devido a problemas com áudio.

As respostas ao questionário foram sumarizadas e discutidas em uma sessão online síncrona com os três docentes e os três assistentes. Como resultado da discussão e das lições aprendidas, identificamos que um período com mais semanas pode ser vantajoso para maior prazo entre as entregas dos blocos. Também identificamos que, além das aulas síncronas, gravadas para posterior consulta, é positivo oferecer encontros adicionais para conversação sobre tópicos específicos. Para esses encontros, em vez de gravação na íntegra, é vantajoso gravar resumos da conversa em vídeos curtos de 5-10 minutos. Para o Bloco 3, cada fase foi apoiada por um encontro em que as pessoas se reuniam para discutir as atividades e um(a) docente guiava a conversa; ao final, todas as pessoas presentes ajudavam a construir, por mensagem textual ou voz, um script contemplando os principais pontos a serem explicados no vídeo resumo. $\mathrm{O}(\mathrm{a})$ docente, então, utilizava esse script para criar o video resumo sobre o encontro e todas as pessoas presentes podiam complementar enquanto o vídeo era gravado ao vivo. Essa dinâmica se mostrou muito produtiva e capaz de engajar as pessoas presentes.

Também identificamos que é positivo ter a agenda com entregas definidas desde o início, mantendo o atendimento de dúvidas via fórum e durante os encontros síncronos. Como acertos e ações a serem mantidas, identificamos a dinâmica de sala de aula invertida, o uso de emblemas, a utilização de desafios, a flexibilidade das entregas em três prazos (um para cada bloco) e as explicações detalhadas sobre as atividades. Também concluímos que a avaliação focada no atendimento dos requisitos e na execução das atividades no prazo, aliada à autoavaliação discente, é um caminho positivo. Cada disciplina demanda uma estratégia de avaliação adequada ao seu propósito, adotando avaliações adequadas a cada atividade e a cada habilidade a ser exercitada. Por isso, argumentamos que, para essa disciplina, as avaliações devem continuar focando mais nas justificativas e explicações discente (o porquê fez como fez) do que no resultado final propriamente dito.

Como pontos a melhorar, identificamos a necessidade de um questionário demográfico no início da disciplina e outros meios para informações e opiniões durante a sua condução de modo que seja possível realizar eventuais ajustes. As aulas síncronas demandam mais planejamento e estratégias de promover a participação discente: notamos que as aulas com maior interação adotavam uma dinâmica no estilo bate-bola entre docentes e discentes, algo no estilo de bate-papo ou painel. Também identificamos a necessidade de termos encontros mais curtos e focados, com um número maior de encontros de menor duração. Como reestruturação, consideramos ser necessário mais tempo para discutir o caso do Robô, e que pode ser benéfico migrá-lo para o Bloco 1 de modo a promover a investigação e discussão ética no contexto de diferentes áreas da Computação. Finalmente, será feito novamente um trabalho de curadoria do conteúdo para indicar um subconjunto de materiais de leitura obrigatória, com outras indicações para aprofundamento.

\section{CONCLUSÃO}

Neste artigo apresentamos uma disciplina de Introdução à Ciência da Computação que oferecemos como disciplina curricular obrigatória no primeiro semestre do nosso curso de Bacharelado em Ciência da Computação na Universidade Federal do Paraná. Para ilustrar a disciplina, apresentamos sua ementa e descrevemos sua aplicação em versão remota no segundo semestre de 2020. A disciplina foi criada para exercitar 17 habilidades que consideramos importantes para serem trabalhadas com discentes ingressantes em nosso curso, cobrindo três eixos: da introdução à Computação e suas áreas, ao pensamento computacional e a visão sistêmica e responsável. Os resultados da condução da disciplina no formato remoto revelam que tivemos êxito em promover as habilidades que valorizamos, e nos sugerem ações de melhorias para ofertas futuras.

Consideramos que nosso conjunto de 17 habilidades, junto com a ementa da disciplina e seu conteúdo programático, são contribuições importantes deste artigo, que podem auxiliar outros cursos e docentes com demandas e interesses semelhantes. As estratégias didáticas que adotamos também têm potencial de inspirar outras iniciativas, especialmente no que diz respeito à necessidade de trabalhar as habilidades de colaboração, autonomia e as questões éticas e de responsabilidade profissional, de forma articulada com problemas e desafios.

\section{AGRADECIMENTOS}

Os autores agradecem especialmente os assistentes da disciplina, Flávia Sayane Meireles, Leonam Cordeiro de Oliveira e Mariane Sponchiado Cassenote por todo o apoio e contribuição na condução da disciplina, e a Carolina Moreira pelo apoio com os Desafios. Os autores agradecem também os/as discentes da disciplina que responderam o questionário e deixaram insumos valiosos para a melhoria da disciplina, e os/as colegas docentes do Departamento de Informática da UFPR pelas discussões continuadas sobre o tema. 


\section{REFERÊNCIAS}

[1] Daiane Andrade, Tainã Carvalho, Jayne Silveira, Simone Cavalheiro, Luciana Foss, Ana Marilza Fleischmann, Marilton Aguiar, and Renata Reiser. 2013. Proposta de atividades para o desenvolvimento do pensamento computacional no ensino fundamental. In Anais do Workshop de Informática na Escola, Vol. 1. 169-178.

[2] Tim Bell, Ian H Witten, Mike Fellows, Robyn Adams, and Jane McKenzie. 2011. Ensinando Ciência da Computação sem o uso do computador. Computer Science Unplugged ORG (2011).

[3] Ted Boren and Judith Ramey. 2000. Thinking aloud: Reconciling theory and practice. IEEE transactions on professional communication 43, 3 (2000), 261-278.

[4] Carlos Rodrigues Brandão. 2017. O que é método Paulo Freire. Brasiliense.

[5] Tim Brown. 2020. Design Thinking: uma metodologia poderosa para decretar o fim das velhas ideias. Alta Books.

[6] Randy Connolly. 2020. Why computing belongs within the social sciences. Commun. ACM 63, 8 (2020), 54-59.

[7] Richard G Epstein. 1997. The Case of the Killer Robot Stories About the Professional, Ethical, and Societal Dimensions of Computing. (1997).

[8] Bruna Ferreira, Williamson Silva, Edson Oliveira, and Tayana Conte. 2015. Designing Personas with Empathy Map. In International Conference on Software Engineering and Knowledge Engineering (SEKE), Vol. 152.

[9] Cléuzio Fonseca Filho. 2007. História da computação: O Caminho do Pensamento e da Tecnologia. EDIPUCRS.

[10] Lucia Maria Martins Giraffa and Luana Müller. 2017. Methodology based on flipped classroom and problem solving related to students' habits: a proposition for teaching programming for beginners. Journal on Computational Thinking (fCThink) 1, 1 (2017), 52-67.

[11] Don Gotterbarn, Keith Miller, and Simon Rogerson. 1997. Software engineering code of ethics. Commun. ACM 40, 11 (1997), 110-118.

[12] Mark Guzdial. 2015. What's the best way to teach computer science to beginners?

[13] Association for Computing Machinery (ACM) Joint Task Force on Computing Curricula and IEEE Computer Society. 2013. Computer Science Curricula 2013: Curriculum Guidelines for Undergraduate Degree Programs in Computer Science. Association for Computing Machinery, New York, NY, USA.

[14] Donald E Knuth. 1974. Computer science and its relation to mathematics. The American Mathematical Monthly 81, 4 (1974), 323-343.

[15] Eleandro Maschio Krynski. 2013. Modelagem do processo de aquisição de conhecimento apoiado por ambientes inteligentes. (2013).

[16] Carla Leitão, Cristiano Maciel, Lara Schibelsky Godoy Piccolo, Luciana Salgado, Patricia C de Souza, Raquel Prates, Roberto Pereira, and Vinicius Carvalho Pereira. 2017. Human Values in HCI: a challenge for the GrandIHC-BR. In Proceedings of the XVI Brazilian Symposium on Human Factors in Computing Systems. 1-6.

[17] Bryan W Mattimore. 2012. Idea stormers: How to lead and inspire creative breakthroughs. John Wiley \& Sons.

[18] Brent Daniel Mittelstadt, Patrick Allo, Mariarosaria Taddeo, Sandra Wachter, and Luciano Floridi. 2016. The ethics of algorithms: Mapping the debate. Big Data \& Society 3, 2 (2016)

[19] Carolina Moreira Oliveira, Roberto Pereira, Ludmilla Galvão, Leticia Peres, and Ermelindo Schultz. 2019. Utilização de Desafios para o Desenvolvimento do Pensamento Computacional no Ensino Superior: um relato de experiência. In Brazilian Symposium on Computers in Education (Simpósio Brasileiro de Informática na Educação-SBIE), Vol. 30. 2005-2014.

[20] Andrey Ricardo Pimentel and Alexandre Ibrahim Direne. 1998. Medidas cognitivas no ensino de Programaçao de Computadores com Sistemas Tutores Inteligentes. Revista Brasileira de Informática na Educaçao (IE) 3 (1998), 17-24.

[21] Clive Thompson. 2019. The secret history of women in coding. The New York Times Magazine 13 (2019).

[22] Bill Tucker. 2012. The flipped classroom. Education next 12, 1 (2012), 82-83.

[23] Marcel Van der Klink, Jo Boon, and Kathleen Schlusmans. 2007. Competências e ensino superior profissional: presente e futuro. Revista Europeia de Formação Profissional 40, 1 (2007), 72-89.

[24] Corrie Van der Lelie. 2006. The value of storyboards in the product design process. Personal and ubiquitous computing 10, 2-3 (2006), 159-162.

[25] Jeannette M Wing. 2006. Computational thinking. Commun. ACM 49, 3 (2006), 33-35.

[26] Avelino Francisco Zorzo, Daltro Nunes, Ecivaldo Matos, Igor Steinmacher, Renata Mendes de Araujo, Ronaldo Correia, and Simone Martins. 2017. Referenciais de Formação para os Cursos de Graduação em Computação.

\section{MATERIAIS DE APOIO}

Para facilitar a replicação do nosso estudo em outros contextos, disponibilizamos o acesso aos materiais de base, aos dados brutos da avaliação, a vídeos produzidos durante a condução do Bloco 3, e a uma instância modelo da disciplina no sistema Moodle que viabiliza a importação e utilização por outras pessoas.
- Dados do questionário de avaliação: apresenta os dados anônimos brutos sobre a avaliação da disciplina pelos discentes.

- Instância Moodle configurada para a disciplina: possibilita a importação e reutilização do curso, disponibilizando os materiais, agenda, emblemas, jogos e desafios.

- Relatório Técnico para a proposição da disciplina de Introdução à Ciência da Computação: apresenta uma síntese do estudo para a proposição da disciplina.

- Vídeos dos projetos das equipes: quadro na ferramenta Padlet com alguns dos vídeos produzidos por discentes nos projetos para o Bloco 3. 